\title{
Exploring Researcher Vulnerability: Contexts, Complications and Conceptualisation
}

\begin{abstract}
Research involving vulnerable consumer populations is on the increase and understanding the social consequences of consumption within different marketing contexts has become a common theme across Consumer Culture Theory, Transformative Consumer Research and Critical Marketing. Yet the diverse difficulties faced by researchers who investigate consumer vulnerability have not been sufficiently addressed. In line with the need for greater reflexivity in research, this paper reflects on our own research experiences and highlights the complexities associated with conducting research on sensitive topics in challenging contexts. With reference to such experiences, we illustrate the phenomenon of researcher vulnerability and discuss its implications for knowledge generation within the marketing domain.
\end{abstract}

Keywords: researcher vulnerability, vulnerable consumers, interpretivist research, knowledge generation 


\section{Introduction}

Research involving vulnerable consumer populations is on the increase and understanding the social consequences of consumption within different marketing contexts has become a common theme across Consumer Culture Theory, Transformative Consumer Research and Critical Marketing (Arnould and Thompson, 2005; Mick, 2006; Tadajewski, 2010). Yet the diverse difficulties faced by researchers who investigate consumer vulnerability have not been sufficiently addressed. We have all conducted independent studies involving vulnerable consumers. Through discussion it became apparent that our four studies converged, not simply in our interpretivist theoretical lens, but also in terms of the vulnerabilities we encountered. In line with the need for greater reflexivity in research (Miller et al., 1998; Thompson, 2002; Denzin, 2003; Brown, 2004; Bettany and Woodruffe-Burton, 2009; Dickson-Swift et al., 2007, 2008, 2009), this paper reflects on our own research experiences in order to highlight the complexities associated with conducting research on sensitive topics in challenging contexts.

Such challenges, as the extant literature reveals, have been explored by the wider disciplines of psychology (Sieber and Stanley, 1988; Banyard and Flanagan, 2006), education (Tillman, 2002; Seidman, 2006), sociology (Miller et al., 1998; Brackenridge, 1999; BirenbaumCarmeli et al., 2008), public health (Alty and Rodham, 1998; Dickson-Swift et al., 2007, 2008, 2009), and social research (Lee and Renzetti, 1990; Lee-Treweek and Linkogle, 2000). By joining this conversation we seek to highlight its relevance to contemporary marketing research and offer insights into the ways researchers construct knowledge about vulnerable consumers. Our key contributions are twofold: 1) through reflecting on our research experiences, we discuss the challenges we confronted. By doing so, we outline the often 
overlooked concept of 'researcher vulnerability'. 2) We explore the impact of such vulnerability on the construction of knowledge.

Our paper is organised as follows. We begin with a discussion of the importance of researching vulnerable consumers to the development of theory and practice in marketing. Next, in light of literature on sensitive research, we discuss some of the key challenges of investigating sensitive topics and their impact on knowledge production. The method section outlines our research contexts and provides a brief account of the research approach employed for this paper. We then present data from our individual narratives to illustrate themes of 'emotion and disempowerment', 'shifting power dynamics', and 'personal safety'. Before concluding the paper, we discuss the implications of our study for a variety of stakeholders whose institutional practices influence knowledge generation in the field of marketing.

\section{Vulnerable consumers}

Vulnerable consumers experience powerlessness and a dependence on external factors (i.e., marketers) to participate in marketplace activities (Baker et al., 2005; Andreasen and Manning, 1990). Vulnerability can occur across diverse consumption contexts due to the interaction between individual and environmental factors - "when barriers prohibit control and prevent freedom of choice' (Baker et al., 2005, p. 135). It is recognised that not all consumers have equal access to marketplace resources. For instance, low-income consumers encounter exchange restrictions that constrain participation in mainstream consumption culture (Alwitt and Donley, 1996, Hill, 2001; Hamilton and Catterall, 2006). There are also those whose everyday life consumption experiences are regulated by institutional forces (Arnould and Thompson, 2005; Jafari and Goulding, 2008, 2012). Similarly, research 
involving disabled consumers (Mason and Pavia, 2006a and b; Downey and Catterall, 2007), those suffering from serious illness (Hunter-Jones, 2010) and those experiencing bereavement (Canning and Szmigin, 2010) paint a picture of lives overshadowed by uncertainty, immobility and social exclusions. Researchers investigating vulnerable consumers tend to move away from a market-centred world view to a more society-centred focus (Peñaloza and Venkatesh, 2006), a focus which can liberate marketing from its micro environment (i.e., simply managerial implications) and re-establish society as its macro habitat; this macro-perspective is more suited to addressing individuals' life challenges (Firat and Dholakia, 1997; Tadajewski, 2010). This stream of research does not aim to simply arouse feelings of sympathy in its audiences; rather, it seeks to instigate action. It offers a deeper insight into how vulnerable consumers feel about their lives, consumption practices, and multiple interactions with markets, marketing, and other market-influencing institutions (e.g., governments, regulatory bodies, NGOs, media). This body of research questions takenfor-granted assumptions about the nature of markets and the operationalisation of marketing practices (Peñaloza and Venkatesh, 2006). It offers policy implications and enables marketers to recognise, understand, and respond, in a humanistic way, to the diverse needs of consumers (for example, Hill, 2005). Therefore, identifying the difficulties of researching in these contexts should be regarded as a decisive step towards future knowledge construction.

\section{Research in a sensitive context}

For the sake of our discussion, we define sensitive research as 'research which potentially poses a substantial threat to those who are or have been involved in it' (Lee, 1993, p.4). There is a general consensus (Lee, 1993; Lee and Renzetti, 1993; Miller et al., 1998; Lee-Treweek and Linkogle, 2000; Dickson-Swift et al., 2008) that sensitive research covers a wide range of 
topics such as poverty, sexual behaviours, death, illness, gender power relations, religion, ethnicity, migration, drug and alcohol addiction, bullying, domestic violence, disability, and political intolerance. These topics incorporate elements of emotional, psychological, or physical anxiety as they represent some of the most pressing human problems (Lee and Renzetti, 1993). As a result, those involved in conducting sensitive research can experience differing measures of vulnerability which can in turn influence both the researcher and the research process (Dickinson-Swift et al., 2007; Downey et al., 2007). Although not all researchers experience (the same type and degree of) vulnerability, we must appreciate the potential impact of undertaking such projects on researchers (Liamputtong, 2007). Depending on the research context (see, Hill, 1995), vulnerabilities may influence researchers in their engagement with, and understanding of, the research phenomena and in their production and dissemination of knowledge. It is therefore imperative that the impact of these challenges be understood from the perspective of the researcher.

As we contend, researchers investigating sensitive topics are exposed to the highly emotive situations and sometimes life-threatening conditions of their participants; and as a result are susceptible to experiencing participant-like emotions (Alty and Rodham, 1998). As such research becomes 'emotion[al] labour', where the sustained engagement/immersion in the research context can be instrumental in the researcher experiencing emotional and psychological distress (Dickson-Swift et al., 2009 after Hochschild 1983). These experiences can be short lived or may endure well beyond the research process (Dunn, 1991; Stone, 2009). In addition, researchers may suffer from feelings of 'guilt' or 'betrayal' (Lofland and Lofland, 1995; Dickson-Swift et al., 2007) upon leaving participants at the end of the field work period. However, in doing so, and in order to get work published, focus falls on research rigour at the expense of reflecting on emotional well-being (Dickson-Swift et al., 
2009). These difficulties affect researchers' decisions on whether or not to engage in such challenging contexts. While some researchers embrace risk to study sensitive topics, others avoid such controversial research topics simply because they are problematic. This avoidance, Sieber and Stanley (1988) contend, evades a responsibility to address sensitive topics. As such, some authors (i.e., Sieber and Stanley, 1988; Lee and Renzetti, 1993 and Dickson-Swift et al., 2008) advise that knowledge can only be extended/enhanced through documenting challenges particular to the sensitive research domain. Our reflections form part of this documentation as they bring to the fore the barriers and vulnerabilities we encountered throughout our studies. Traditionally, institutional forces (e.g., publishers, research committees, journal editors, and funding bodies) disregard the role played by emotion in knowledge production (Dickson-Swift et al., 2009). This traditional ideology is questioned by the current upsurge in interest in unseen aspects of the research process suggesting that a shift in institutional thinking is required to accommodate new perspectives (see Hogg and Maclaren, 2008; Bettany and Woodruffe-Burton, 2009).

\section{The interpretive lens and knowledge generation}

Interpretive research offers an appropriate means by which to address sensitive topics (Liamputtong, 2007). Interpretivism translates into research approaches that support a close researcher-researched relationship. The initiation of such rapport is considered a key factor in the elucidation of knowledge (Dickson-Swift et al., 2009). As such, immersion in the context of the research is vital; Ger and Sandıkçı (2006, p.513) emphasise this point: 'in the case of researching sensitive topics, theoretical reflection and available knowledge can be limited' mainly because 'people tend to conceal their identities and activities.' This immersion can also encourage participants to reveal narratives of self, or as (Hill, 1995, p. 147) indicates, 
becoming 'willing partners and equals', in a 'collective enterprise of knowledge production.' MacInnis (2011, p. 152) also argues that immersion is pivotal to generating new insights as it is through such an approach that we come to understand our participants' everyday realities and 'identify what others have not yet discovered.' MacInnis further contends that 'immersion is rarely encouraged, except among scholars who adhere to the consumer culture theory paradigm' (p.152). In light of such thinking, marketing scholars have started to reflect on and critique the discipline's decline in new knowledge production (Palmer and Ponsonby, 2002).

Our studies employed different interpretive methodological approaches (grounded theory, social constructionism, radical constructivism and phenomenology), yet we held the common desire to get close to and capture the lived experiences of our participants. Knowledge construction based on immersion seeks to encourage marketing researchers to move beyond the protective shells of scientific approaches (Firat and Venkatesh, 1995) and political neutrality (Bettany and Woodruffe-Burton, 2009) and adopt a 'self-reflexive' position. Reflexive practices encourage us to confront the manner in which we consider the world around us and the knowledge we attempt to generate (Peñaloza and Venkatesh, 2006). We are required to consider the research process from new angles and transgress the hierarchical relationships between us (researchers) and them (the researched) (Buttle, 1998). The act of reflexivity highlights 'the knowledge-making practices of researchers as participating in the context under study, actively producing and being produced by that context, not merely documenting and observing' (Bettany and Woodruffe-Burton, 2009, p.663). Such practices allow researchers to critically monitor their own roles and ways of thinking at different stages of their inquiry (i.e., pre, during and post) (Hertz, 1997). The following discussion depicts 
such a critical reflection from a retrospective perspective - looking back to reflect on experiences of vulnerability encountered in completed research projects on sensitive topics.

\section{Method}

Each of us have conducted sensitive research with vulnerable populations and experienced particular forms of vulnerability. In this section, we briefly explain the way we constructed themes to reflect these dimensions of vulnerability. However, given the importance of context to knowledge generation (Askegaard and Linnet, 2011), we would like to briefly elaborate on the contextual perspective of each author's research.

Author 1's research involved investigating Iranian young adults' lifestyle choices and identity construction in the context of cultural globalisation. Due to the political dynamics of the country, issues of identity in Iran are regarded as politically sensitive (Jafari and Goulding, 2008, 2012). In the eyes of Iranian authorities, the 'Imperialist West' attempts to weaken the Islamic society's cultural integrity by promoting 'decadent' Western lifestyles and ideologies. It is also believed that the West's project of 'cultural invasion' rests upon intelligentsia to promote the ideas of liberalism and secularism amongst the young population of the country. On this basis, Iranian authorities have created an ideological divide between 'khodi' (those who are one of us) and 'gheir-e-khodi' (those who are not one of us) (Khosravi, 2008). This means that if someone (e.g., a researcher or author) is categorised as 'gheir-e-khodi', that person could be accused of helping the enemy's (the West) project of 'cultural invasion', and consequently be detained. It was in such a context that he conducted 28 depth interviews and 4 focus groups with young adults aged 18-33. 
Author 2's project employed a phenomenological approach to explore the collective experience of illness (Thompson et al., 1989). The context for this investigation was the US Myeloma community; particularly a network of 3 patient-led, community-based support groups in the Mid-west, accessed through a group leader who acted as gatekeeper. Myeloma is an incurable form of bone marrow cancer. Patients may have the disease for several years and it is characterised by cycles of active disease and remission (Durie, 2003). A period of contextualisation, drawing on informal interviews with community members and communityproduced secondary data, was followed by non-participant observation at support group meetings over a period of 4 months. Subsequently 20 face-to-face depth interviews were carried out with 15 Myeloma patients and their spouses or family members - "carers", as they are known. Through this study attention was drawn to the under-explored phenomenon of collective enablement of self-identity. The personal movement revealed by participants is from a position of passivity, fear and objectification to one of perceived control, understanding and skilled navigation of the healthcare market.

Author 3's research involved in-depth interviews with low-income families to explore the coping strategies they employed in response to experiences of relative poverty in consumer culture. The study was based on visiting 30 families in their homes, talking to parents and children over the age of 11 . The majority of the families were headed by single mothers and all clearly fell below the poverty line with an average weekly income of $£ 150$. Key themes arising from data collection were experiences and impact of stigmatisation, social exclusion, children's well-being, consumer agency and coping responses to material and social deprivation. This research was conducted in urban areas of Northern Ireland and many of the participants lived in areas associated with high crime levels and anti-social activity. 
Author 4's research involved three individual cases of homebound consumers that were explored over a two-year period by means of ongoing conversational style interviews. The lived consumption experiences that these homebound consumers employed to retain an identity in absence of direct marketplace interaction, was the focus of the study. Far from being the powerless, weak, and feeble consumers generally depicted in literature (Hanson, 2002; Murphy, 1990; Phillips, 1990), the homebound consumers in this study overcame many challenges to remain active, powerful, independent agents of change. This shift in perspective from a purely 'architectural' form of consumption to one of understanding the micro-level of lived consumption experiences serves to extend knowledge of vulnerable populations. The research was conducted in Northern Ireland, a context in which 'ethnoreligious identity' (Todd et al., 2009) had particular significance for the researched and the researcher.

While conducting research in such contexts, we experienced many challenges. Yet, it was only on reflection after completing our research projects that we realised the value in sharing our experiences with peers; recognising that such challenges can influence the nature and direction of knowledge generation and diffusion. Our 'research journeys' (Gadon, 2006) were individual, yet in order to systematically theorise our experiences we move beyond our individual perspectives and attempt to find convergence. Our initial step was to deconstruct and understand our research experiences through compiling individual narrative reflections. These narratives were constructed as "our stories" and then shared with one another; they comprise the data presented here. Manual data analysis was then conducted with part to whole analysis procedures identifying key themes, experiences and emotions across the transcripts (Miles and Huberman, 1994). To achieve this, we worked as an interpretive 
community (Thompson, 2002), agreeing as a group on emergent themes and triangulating these with the extant literature.

\section{Emergent themes}

Having contextualised the study, we now draw key themes from the data to enable us to extend understanding of the concept of researcher vulnerability. We offer the following set of themes as an 'illustration' of the lived experience of researcher vulnerability. We use the term 'illustration' deliberately as what follows is not intended to offer a definitive account of researcher vulnerability, to do so would risk being consumed by 'the vortex of narcissism, pretentiousness and infinite regress' which Finlay and Gough (2003, in Bettany and Woodruffe-Burton, 2009, p.675) identify as a key danger of poor reflexive practice. Therefore we acknowledge the subjectivity of researcher vulnerability - the type and degree of vulnerability depends on many factors including the researchers' experience and skills, their level of immersion in their research contexts, and the characteristics and circumstances of their participants.

\section{Emotion, disempowerment and vulnerability}

The first theme we draw on relates to the emotional impact of our research work with vulnerable consumers, an issue that is routinely 'undervalued within the university culture' (Dickson-Swift et al 2008, p 345.). Emotional challenges and responses can be seen across the various stages of the research process from the first attempts to gain fieldwork access to data analysis and presentation of findings. Across our narratives we depict a variety of emotional responses to aspects of the research process; among them are fear, anxiety, sadness, frustration, grief and guilt. We highlight that such emotional responses are a source of researcher vulnerability, negatively affecting researcher well-being. Some emotional 
challenges are short-lived while others, such as the sadness at a participant's passing, remain with us and colour our research projects, in terms of knowledge construction and dissemination.

\author{
"When you begin to unpick the discourse of those considered \\ vulnerable, it is expected that some of the emotional turmoil will \\ 'cling' to you." (Researcher 4)
}

This recalls Warr's (2004) notion of 'emotional weight' of the stories we encounter in the field. Warr describes how particular stories stay with us and are 'carried around' by the researcher. A key source of emotional labour (Hochschild, 1983 ) came from our responses to interview content, stories of hardship, loneliness, pain and powerlessness. For example, Researcher 3 describes the complex realities of participants' lives and the sometimes shocking narratives that emerged during interviews:

"I talked to a father and his 16 year old daughter who were grieving after the death of their wife and mother respectively, a single mother whose sister committed suicide 3 weeks before I met her, women who had separated from their partners and a young mother who had an unhappy and unstable childhood. I heard stories of loneliness, depression, illicit income and fears for the future. Poverty was only one part of their lives and I went into interviews never quite knowing what direction the conversation would take and what would be revealed."

As this reveals, another aspect of our experiences of vulnerability was the unexpected nature of it and, in some cases, our lack of preparedness to deal with the emotional impact of our work. Sometimes emotions are provoked by a specific incident or particular participant or sometimes it is the cumulative effect of hearing multiple stories of participant vulnerability that can overwhelm us. We entered participants' lived environments and often it was the 


\begin{abstract}
"situated" and "embodied" nature of our data collection (Warr, 2004) that intensified such emotional responses:
\end{abstract}

"While both the media and previous literature had warned me about the negative consequences associated with poverty, I was now encountering these stories face-to-face. Rather than reading about the number of people living in poverty in the newspapers I was meeting real people, and putting names to stories which undoubtedly intensified emotional reactions." (Researcher 3)

Our narratives reveal that empathy is central to both the collection of good quality data and to the experiencing of vulnerability. Hoffman (2000, p.30) recognises that empathy can, 'make a person have feelings that are more congruent with another's situation than with his own.' The ability to create empathetic connections is a key skill when working with vulnerable populations (Woodby et al., 2011); yet, empathy can expose the researcher to episodes of emotional stress and powerlessness (Watts, 2008):

"Difficult situations experienced by the homebound consumers leave emotional scars. What would be experienced as fleeting moments of sadness in the course of conducting interviews very easily escalated into particular dark episodes of empathy." (Researcher 4)

The emotional impact of the research encounter is central to the level and intensity of vulnerability experienced by researchers. Our narratives tell of the dual role of empathy. Clearly, empathetic responses aid the researcher in creating a rapport with participants and in building an understanding of their lived experiences. However, such bonds can leave the researcher emotionally vulnerable:

\footnotetext{
"Through attempts to empathise with informants I feel I assimilated the threats and risks recounted - the fear of illness, concerns about relapse from remission, the inevitability of death and dying." (Researcher 2)
} 
Researcher 2 describes how her fear of illness was amplified during the fieldwork period and extended beyond those involved in her research to her wider community of family and friends. The research process not only exposes researchers to the difficult lived experiences of participants but can also be the catalyst to an exploration of our own fears and insecurities. Qualitative research can be viewed as a 'life-changing' process which provides the researcher with 'opportunities to assess certain aspects of their lives' (Dickson-Swift et al., 2007, p.342). Similarly, Researcher 3 recalls that interaction with vulnerable consumers encouraged 'personal reflection' contrasting her own 'position, choices and abilities' with that of her informants.

It is important to recognise that vulnerability and emotional impact can extend well beyond the fieldwork period as the researcher moves through data analysis and presentation of findings:

"The complex emotions I experienced while collecting the data were re-lived and recounted through the passing months and years when I conducted manual data analysis. On reflection I realise that during both the data collection and analysis phases I engaged in an amount of emotional management. Storing away sadness and fear during the exhilarating fieldwork phase only to be unexpectedly revisited by it during the long and lonely phases of data analysis." (Researcher 2)

The act of replaying recordings and transcribing participants' words can elicit new emotional responses or recall past negative episodes (Stone, 2009). Woodby et al. (2011) describe how, what they term 'researcher distress', can be heightened by the cumulative process of coding sensitive material. Researchers are 'exposed' to distressing material repeatedly as the iterative and repetitive process of qualitative analysis is undertaken. Such emotional 'exposure' can 
lead to exhaustion, stress, isolation and increased vulnerability (Woodby et al., 2011, p. 833) limiting the researcher's ability to analyse data (Dickson-Swift et al., 2008).

Researcher 2 describes feeling 'disempowered' by 'strong emotions' linked to the fear and grief she experienced. This sense of powerlessness extended to coping strategies. The notion of disempowerment is important, here we see that the emotions encountered in the field and beyond create a barrier to reflexive practice:

"During the entire $\mathrm{PhD}$. process I felt unable to reflect on the grief I felt at learning of the death of another informant. My need for emotional management made any sort of reflexivity incredibly difficult; though of course this practice should have been central to my methodology."

Researcher 2's reluctance or inability to meet strong emotions such as grief and fear head-on rendered her reflexive practice impossible. There is acknowledgement (e.g., Warr, 2004; Woodthorpe, 2007) that reflecting on these emotional responses would have deepened and enriched the study's findings yet this aspect of the research encounter is left unreported. Through this narrative we can see that grief and loss have affected this researcher's emotional well-being and her ability to put into words her reflective thoughts. She describes how her attempts at emotional management - what we might, in the vernacular, term as "bottling up" - impeded the research process:

"My lead informant and gate-keeper died on $2^{\text {nd }}$ August 2009, one month before the $\mathrm{PhD}$ was to be handed in. I knew he had gone but couldn't bring myself to open the email that would confirm it. I didn't want to see the words - I feared they may paralyse me; that my grief would suck away my ability to complete the thesis." 
For researcher 4, such "bottling up" of emotions was also evident, albeit for a different reason. She found particular episodes of vulnerability she encountered with her most physically disabled participant, a continuous and often heart-wrenching struggle. Trying to 'keep a lid' on everything was important for the well-being of that participant and she had to suppress and disguise her emotions whilst in his company:

"In the safety of my car I would cry and rage against the inadequacies of the care system. Knowing the intimate details, the people involved, the realities left me completely speechless and powerless."

Watts $(2008$, p.11) talks of the need for 'emotional protection' and describes the sensitive research process as one of balance between becoming too close to the research participant and being too distant. Too much distance may mean that the lived experience of participants becomes obscured yet becoming too close can lead to undesired emotional involvement, or the converse - desensitisation (see for example, Scott, 1998). Dickson-Swift et al. (2009, p.62) remind us that emotions have both a 'feeling' and a 'thinking' element. Similarly, we argue that emotions can be seen as resources that are good to think with. Our humanness shines through in the extracts above and we suggest that the experiencing of these emotions was an important element of the research process - an element which has allowed us to move closer to our participants' lived experiences and ultimately enrich the contribution of our studies.

\section{Shifting Power Dynamics and Vulnerability}

While it may be perceived that researchers occupy a dominant position in relation to the research process, each of us experienced shifting power dynamics during our studies. Drawing on Reay (1996, p. 443), the 'difficult differences' of the power relations between the researcher and the researched need to be acknowledged. However, acknowledging difference 
is not simply about recognising diversity but 'exposing privilege' (Strickland, 1994, p. 271) and understanding how this impacts on knowledge construction. The concept of power in these studies manifested itself in various ways; the power of a male researcher engaging with female participants in a Muslim society, material power when engaging with those living in poverty and power of the able-bodied when engaging with those who are considered disabled or terminally ill. Equally, we acknowledge an academic power in terms of our ability to produce/not produce certain knowledge about participants' lives.

It is widely recognised that much of the endeavour of qualitative fieldwork centres on issues of access, rapport and relationship building (Van Mannen, 2011). Researcher 1, for example, discusses how his fieldwork depended on his participants' trust in him:

"In my research I was interested in those less visible aspects of my participants' lives, things that have been either overlooked or misunderstood simply because their voices are not heard. In order to achieve this, I needed to be seen as an 'insider', someone they could trust and share their true experiences with."

Our narratives highlight that these issues are more than mere practical considerations but rather can be a significant source of researcher vulnerability. We had the power to decide what questions to ask during data collection, the power to select what data to use and how it should be interpreted and the power to decide how and to whom our findings were presented. Such power is the privilege of the researcher but it can also foster feelings of guilt and uncertainty:

"I had very mixed feelings about accessing this level of detail about my respondents' lives. On the one hand I was grateful and overwhelmed by how much they were willing to share with me and enthusiastic that their stories were generating good quality and valuable data for my $\mathrm{PhD}$. On the other hand, I sometimes worried 
that I was encouraging respondents to reveal too much about themselves by talking about such sensitive issues. I was clearly benefiting significantly from them but what were they getting from me?" (Researcher 3)

"Often interviews would emotionally deplete me. I felt keenly the guilt of the well, taking something from the ill." (Researcher 2)

We continue to feel a responsibility to our participants in terms of accurately representing their lives. As Researcher 2 reflected, "taking on the weight of re-telling their stories of struggle and hope was, and is, a daunting responsibility." Further, despite recognising it was not the researcher's role, we describe feeling powerless to resolve or ameliorate the difficulties in participant lives:

"I was only too aware of the emotional roller coaster I would be riding, immersed in such a research context. But I found myself quite at sea early on in the research process; my inability to realise anything positive for Jay [research participant], called my sense of moral judgement into question." (Researcher 4)

"My participants' trust in me deserves my honestly returning their favour. The question that I still ponder is: what can I do for them?" (Researcher 1)

The frustrated desire for reciprocity is expressed here in the powerlessness to affect positive change for informants - similar to vulnerable consumers, vulnerable researchers experience powerlessness depending on the dynamics of the research context (Baker et al 2005).

\section{Personal safety and vulnerability}

Our desire to get close to participants meant that each of us carried out data collection in the field, that is, in participants' homes or a preferred location in their lived environments. As 
such, researching vulnerable consumers can take researchers to unfamiliar places, areas of high crime and regions of political or religious conflict (Miller et al., 1998). This can result in both risks to personal safety and feelings of dislocation (Liamputtong, 2007):

"I was going to areas of the city that I had never visited before. In many cases these neighbourhoods were associated with high levels of crime which made me anxious and nervous about the journey to participants' homes. I mainly travelled to interviews by bus and walked the remainder of the way having memorised the route from the bus stop to the house using my A-Z street map. Sometimes talking to participants only heightened my anxiety for the return journey as they told me about divided communities, joyriding, crowds of youths and petrol bombs." (Researcher 3)

For Researcher 3, prior knowledge about the field heightened fear and anxiety when entering potentially unsafe areas, a feeling that became all consuming prior to conducting evening interviews. Geographic location also presents challenges to data collection practices due to constraints imposed by politicised research contexts:

"I was aware of the potential risks imposed on my participants and myself. For example, in Iran it is not unusual that when a young man and a woman are sitting together in a café, the morality police may arrive to ask about their relationship. If the couple are not related through kinship or marriage, they may be taken to the police station to explain why they are together as, in the eyes of the authorities, this is regarded as un-Islamic...also, in a country where authorities are concerned with the theory of 'cultural invasion', I could be seen as the enemy, and by the time it was proved that I was a genuine academic simply collecting data for my own research, I could risk detainment." (Researcher 1)

Our feelings of vulnerability in relation to physical safety are partly explained by our outsider status in the research context, a central theme across our narratives and a common experience of those working with the vulnerable (Allen, 2004): 
"Most of all I felt conspicuous and aware that I was walking around areas where I could be perceived as an outsider because I was not a local resident; areas where outsiders are noticed and where people may be suspicious of strangers and their motives for being there." (Researcher 3)

"Local residents made it their business to find out who I was, what I was doing, where I came from and most importantly, did I represent a threat. Youths would congregate in the area at night; it was commonplace for community demonstrations to take place. Driving through crowds is an intimidating experience and it was difficult not to feel at risk in such areas." (Researcher 4)

Outsider status gives the researcher a vantage point for their observations yet it can also create an uneasy distance between the researcher and the researched (Merton, 1972). This can lead to feelings of conspicuousness and intimidation in the field, heightening both physical and emotional vulnerability. As Researcher 3 revealed, "I never failed to feel tense the day before an interview." With reference to what Ergun and Erdemir (2010) contend about the importance of being seen as an insider by participants, Researcher 1 was in danger of being perceived as a threatening outsider despite being an Iranian conducting research in Iran. This reminds us of the socially constructed nature of relations in that 'the categories with which we as human beings apprehend the world do not necessarily refer to real divisions' (Burr, 2003, p.3). Nevertheless, participants' perceptions of researcher difference can create a barrier to building mutual and empathetic understanding:

"A sense of trust was not easily built as I was essentially viewed as an 'outsider'. Issues of 'cultural affinity' and speaking 'the same language' were indeed important, but they were not enough for inclusion. The socio-cultural atmosphere in Iran has influenced the wearing of masks and perpetuated the cutting off of self. Private lives and public projections can be a world apart. This makes understanding people very difficult. As a researcher you need to get close to 
understand these complexities and paradoxes so that you can avoid clichés." (Researcher 1)

Since participants can sometimes feel uncomfortable with disclosing their true identities and real-life stories to insiders, the researcher's position as an outsider can sometimes be seen as an advantage to knowledge generation (Ergun and Erdemir, 2010). Yet, in our research contexts, this outsider status created multiple vulnerabilities, physical jeopardy being paramount but also feelings of frustration and fear. These feelings, as we have demonstrated, can be associated with the characteristics of the contexts in which we studied vulnerable consumers.

\section{Discussion and Implications}

By way of summarising the emergent themes, we offer a conceptual overview of researcher vulnerability (see figure 1).

\section{Insert figure 1 about here}

Based on our findings, we map out the catalysts, features and potential outcomes of researcher vulnerability. We understand catalysts as conditions which may lead to researcher vulnerability. Catalysts are dependent on the research context and objectives guiding the study so a researcher need not encounter all of these to experience vulnerability. We catalogue the effects of researcher vulnerability which include threats to physical safety as well as emotional responses such as fear, guilt and isolation. Researcher vulnerability can occur at any stage of the research process, at times, unexpectedly and the emotional distress can endure beyond the research period. Researcher vulnerability manifests subjectively and potential outcomes vary in their severity from personal reflection to research burn-out where completion of the research project is in danger. 


\section{Knowledge generation}

In his exploration of reflexivity, Thompson (2002) outlines factors which shape researchers' representations of consumers - historical, social and institutional. To these broad and unseen forces we add emotional factors - specifically researcher vulnerability. In this paper, we provided evidence that researcher vulnerability is heightened by proximity to participants. In line with the interpretivist tradition, we endeavoured to fully immerse ourselves in our chosen contexts. As Warr $(2004,581)$ suggests, 'situating research in a lived environment generates powerful descriptive data, and this is intensified by the embodied interaction of actually sitting down and talking with someone.' Yet we contend that researcher vulnerability represents a complex "dark-side" to such immersion.

However we found a counterbalance to the negatives of emotional immersion in the rich empathetic understanding it affords. As Woodthorpe (2007, p.8) contends, we cannot disregard the issue of emotion in our consideration of the knowledge generation process as it 'informs the way we negotiate, interpret and communicate.' Indeed Woodthorpe (2007) argues that recognition of one's emotional state can add a new lens through which to understand data and the researchers' role in its production. In other words, as Palmer and Ponsonby (2002, p.183) highlight, 'our position determines what we see.' Researchers' emotional responses ultimately allow them to gain a deeper understanding of participants' lives. The experience of vulnerability - of openness - is in some way necessary because it ultimately allows better insight into the lived experiences of our participants. As Emerson et al. (1995, p.216) remind us, '[w]hen we self-consciously apply the reflexive lens to ourselves it can help us to see and appreciate how our renderings of others' worlds are not, and can never be, descriptions from outside those worlds.' 
In our research, we could have employed disembodied approaches such as surveys or netnography that avoid close contact with participants. Such approaches may have reduced discomfort for the researcher; however, they would not have produced the same level of insight into the everyday realities of our participants' lives. Knowledge gained from face-toface contact allows us to experience a gambit of emotions which in turn could help us to better understand our data and our interpretations of such data. The empathetic road to understanding informs and ultimately improves our knowledge generation process.

This deep understanding is important, as Ozanne (2009, p.143) highlights, stressing the wider societal impact of marketing research. For Ozanne marketing researchers are "informed brokers" whose ability to engage with different stakeholder groups, including consumers, businesses, media, and policy makers, creates the potential for "sustainable change." As emphasised by a number of scholars (Creswell and Miller, 2000; Harrington, 2002), the production of knowledge (particularly in qualitative research) relies on the construction and positioning of 'convincing storylines' (Hogg and Maclaran, 2008; Shankar and Patterson, 2001). Acceptance of research depends on the 'amount of depth, detail, emotionality, nuance, and coherence' storylines provide for them (Denzin, 2003, p. 248). The depth of understanding garnered from research immersion significantly adds to credibility with relevant stakeholders (MacInnis, 2011), increasing the societal value of research projects while aiding the realisation of knowledge exchange and research impact. This role of gobetween is an important one, bridging the gap between vulnerable populations and the institutions and market actors which affect them offers the opportunity to challenge commonly held assumptions that prevail about these groups.

\section{Conclusion: The need for social support}


We began this paper with the notion that research with vulnerable populations is increasing in the field of marketing. At a time when funding bodies such as the UK Economic and Social Research Council prioritise business research which has wider social implications; the Transformative Consumer Research movement is promulgating its goal of societal change (Mick, 2006); social marketing has become a powerful force for behavioural modification; and the Research Excellence Framework increasingly looks for "impact" from our work we ask the marketing discipline to recognise the impact such research has on the researcher.

As The Voice Group (2008) recognise, research in marketing has for too long adhered to the "lone researcher" doctrine. $\mathrm{PhD}$ programmes, the academic apprenticeship, train members to work individually or closely with one supervisor rather than collaboratively. Thus, the socialisation of $\mathrm{PhD}$ students represents 'an extreme example of isolation in the search of knowledge' (Wasser and Bresler, 1996, in The Voice Group, 2008, p. 148). This is a dangerous paradigm for those conducting sensitive research. The isolation associated with researcher vulnerability can jeopardise the completion of research projects, not least doctoral studies (Stone, 2009; Woodthorpe, 2007). Dickson-Swift et al (2007) recognise this jeopardy in their recognition of researcher 'burn-out'.

In light of this, we ask that our academic institutions and commercial research organisations recognise that researchers addressing sensitive topics need to receive 'therapeutical support' from their mentors, supervisors, and institutions (Dickson-Swift et al., 2009). Such a support culture would allow researchers to carry out projects in a safe manner and to cope with emotional exposure that may harm their psychological well-being and hamper their research progress. As Kleinman and Copp (1993, p. 2) point out 'researchers learn - through their teachers, texts and colleagues - how to feel, think and act.' Therefore we suggest that 
particular training and support be given to those supervising sensitive projects that they may in turn better support doctoral students and early career researchers. Such support and training is a feature of research projects in the wider social sciences. A starting point for marketing researchers may be organisations such as the Social Research Association (UK) who offer guidelines which focus specifically on the emotional and physical well-being of the researcher - their Code of Practice for the Safety of Social Researchers focuses on researcher well-being and describes how risk-reducing behaviours can be fed into the research design process to provide a framework of support throughout the life of a project.

\begin{abstract}
A further area of concern is that the majority of institutional regulations and ethical approval processes focus on the well-being of 'the researched' with little opportunity for the, brief in our experience, acknowledgement of researcher well-being, or the offer of a framework for emotional support. In the nascent field of sensitive marketing research we are relying on the research skills, emotional strength and inner resolve of willing but unsupported researchers both novice and experienced. While we applaud the self-care practices outlined by other authors (Dickson-Swift et al., 2007, 2008, 2009; Dunn, 1991; Watts, 2008) we call for consolidated institutional support to act as an ameliorative to the isolating effects of researcher vulnerability.
\end{abstract}




\section{References}

Allen, D. (2004). Ethnomethodological insights into insider-outsider relationships in nursing ethnographies of healthcare settings, Nursing Inquiry, 11 (1), 14-24.

Alty, A. and Rodham, K. (1998). The Ouch! factor: Problems in Conducting Sensitive Research. Qualitative Health Research, 8 (2), 275-282.

Alwitt, L.F. and Donley, T. (1996). The low-income consumer: Adjusting the balance of exchange. Thousand Oaks CA: Sage.

Andreasen, A.R. and Manning, J. (1990). The Dissatisfaction and Complaining Behaviour of Vulnerable Consumers. Journal of Consumer Satisfaction, Dissatisfaction, and Complaining Behaviour, 3, 12-20.

Arnould, E.J. and Thompson, C.J. (2005). Consumer Culture Theory: Twenty Years of Research. Journal of Consumer Research, 31 (4), 868-83.

Askegaard, S. and Linnet, J.P. (2011). Towards an Epistemology of Consumer Culture Theory: Phenomenology, Structure and the Context of Context. Marketing Theory, 11(4), $381-404$.

Baker, S.M., Gentry, J.W., and Rittenburg, T. L. (2005). Building understanding of the domain of consumer vulnerability. Journal of Macromarketing, 25 (2), 1-12.

Banyard, P. and Flanagan, C. (2006). Ethical Issues and Guidelines in Psychology. London: Routledge.

Bettany, S. and Woodruffe-Burton, H. (2009). Working the limits of method: the possibilities of critical reflexive practice in marketing and consumer research. Journal of Marketing Management, 25 (7-8), 661-679. 
Birenbaum-Carmeli, B., Carmeli, Y., and Gornostayev, S. (2008). Researching sensitive fields: Some lessons from a study of sperm donors in Israel. International Journal of Sociology and Social Policy, 28 (11/12), 425-439.

Brackenridge, C.H. (1999). Managing myself: investigator survival in sensitive research. International Review for the Sociology of Sport, 34 (4), 399-410.

Brown, S. (2004). Writing Marketing: The Clause That Refreshes. Journal of Marketing Management, 20, 321-342.

Burton, D. (2001). Critical marketing theory: the blueprint? European Journal of Marketing. $35(5 / 6), 722-743$.

Burr, V. (2003). Social Constructionism. Sussex: Routledge.

Buttle, F.A. (1998). Rules Theory: Understanding The Social Construction Of Consumer Behaviour. Journal of Marketing Management, 14 (1), 63-94.

Canning, L. and Szmigin, I. (2010). Death and disposal: The universal, environmental dilemma. Journal of Marketing Management, 26 (11), 1129-1142.

Denzin, N. (2003). Reading and writing performance. Qualitative Research, 3 (2), 243-286.

Dickson-Swift, V., James, E.L., Kippen, S., and Liamputtong, P. (2007). Doing sensitive research: what challenges do qualitative researchers face? Qualitative Research, 7 (3), 327-353.

Dickson-Swift, James, E.L. and Liamputtong, P. (2008). Undertaking Sensitive Research in Health and Social Sciences. Cambridge, Cambridge University Press.

Dickson-Swift, V., James, E.L., Kippen, S., and Liamputtong, P. (2009). Researching sensitive topics: qualitative research as emotion work. Qualitative Research, 9 (1), 61-79.

Downey, H., and Catterall, M., (2007). Autopoiesis and the Home Confined Consumer: The Role of Personal Communities. International Journal of Sociology and Social Policy, 27 $(3 / 4), 175-18$. 
Downey, H., Hamilton, K., and Catterall, M., (2007), Researching vulnerability: what about the researcher? European Journal of Marketing, Vol. 41 No. 7/8, pp. 734-739.

Dunn, L. (1991). Research alert! Qualitative research may be hazardous to your health! Qualitative Health Research, 1 (3), 388-392.

Durie, B.G.M. (2003). Multiple Myeloma: Concise Review of the Disease and Treatment Options. Los Angeles, International Myeloma Foundation.

Emerson, R., Fretz, R., and Shaw, L. (1995). Writing Ethnographic Fieldnotes. Chicago: University of Chicago Press.

Ergun, A. and Erdemir, A. (2010). Negotiating Insider and Outsider Identities in the Field: "Insider" in a Foreign Land; “Outsider" in One’s Own Land. Field Methods, 22 (1), 1638.

Firat, A.F. (2010). Commentaries on the state of journals in marketing. Marketing Theory, 10 (4), 437-455.

Fırat, A.F. and Dholakia, N. (1997). Consumption Patterns and Macromarketing: a radical perspective. European Journal of Marketing, 11 (4), 291-98.

Firat, A.F. and Venkatesh, A. (1995). Liberatory Postmodernism and the Reenchantment of Consumption. Journal of Consumer Research, 22 (3), 239-67.

Gadon, E.W. (2006). My Life's Journey as Researcher. Journal of Research Practice, 2(2). Available from http://jrp.icaap.org/index.php/jrp/article/viewArticle/40/53, accessed on 27 January 2012.

Ger, G. and Sandikci, O. (2007). Doing Research on Sensitive Topics: Studying Covered Turkish Women. In R. Belk (Ed.), Handbook of Qualitative Research Methods in Marketing (pp. 509-20), Cheltenham: Edward Elgar Publishing. 
Hamilton, K. and Catterall, M. (2006). Consuming Love in Poor Families: Children's Influence on Consumption Decisions. Journal of Marketing Management, 22 (9), 103152.

Hanson, N. (2002). On Approval: The Geography of Disabled Women and Work, paper presented at the New Directions in Disability seminar series, Centre for Disability Studies, University of Leeds, UK. April 10, 2002.

Hertz, R. (1997). Reflexivity and Voice. London: Sage.

Hill, R.P. (1995), Researching Sensitive Topics in Marketing: The Special Case of Vulnerable Populations. Journal of Public Policy and Marketing, 14 (1), 143-148.

Hill, R.P. (2001). Surviving in a Material World: Evidence from Ethnographic Consumer Research on People in Poverty. Journal of Contemporary Ethnography, 30 (4), 364-391.

Hill, R.P. (2005). Do the Poor Deserve less than Surfers? An Essay for the Special Issue on Vulnerable Consumers. Journal of Macromarketing, 25 (2), 215-218.

Hochschild, A.R. (1983), The Managed Heart: Commercialization of Human Feeling, Berkley, University of California Press.

Hoffman, M.L. (2000). Empathy and Moral Development: Implications for Caring and Justice. Cambridge University Press.

Hogg, M. and Maclaran, P. (2008). Rhetorical issues in writing interpretivist consumer research. Qualitative Market Research: an International Journal, 11 (2), 130-46.

Hunter-Jones, P. (2010). Consumer vulnerability and exclusion: A study of carers in the tourism marketplace. Journal of Marketing Management, 27 (1/2), 165-180.

Jafari, A. and Goulding, C. (2008). "We are not terrorists!” UK-based Iranians, consumption practices and the 'torn self'. Consumption, Markets and Culture, 11(2), 73-91. 
Jafari, A. and Goulding, C. (2012). Globalization, Reflexivity and the Project of the Self: A Virtual Intercultural Learning Process. Consumption, Markets, and Culture. (iFirst).

Khosravi, S. (2008). Young and defiant in Tehran. Philadelphia, PA: University of Pennsylvania Press.

Kleinman, S. and Copp, M.A. (1993). Emotions and Fieldwork, London, Sage.

Lee R.M. (1993). Doing Research on Sensitive Issues. London: Sage.

Lee-Treweek, G. and Linkogle, S. (2000). Danger in the Field: Risk and Ethics in Social Research. London: Routledge.

Lee, M.R. and Renzetti, C.M. (1990). The Problems of Researching Sensitive Topics: An Overview and Introduction. American Behavioural Scientist, 33 (1), 510-28.

Lee, R. M. and Renzetti, C. M. (1993). The Problems of Researching Sensitive Topics. In C.M. Renzetti and R.M. Lee (eds.), Researching Sensitive Topics (pp. 3-13) London: Sage, London.

Liamputtong, P. (2007). Researching the vulnerable: a guide to sensitive research methods. London: Sage.

Liehr, P. (1989). The core of true presence: a loving centre. Nursing Science Quarterly, 2 (1), $7-8$.

Lofland, J. and Lofland, L. (1995) Analyzing social settings. Belmont, CA: Wadsworth.

MacInnis, D.J. (2011). A Framework for Conceptual Contributions in Marketing. Journal of Marketing, 75(4), 136-155.

Mason, M. and Pavia, T. (2006a). The Impact of a Special Needs Child on the Consumer Behaviour of the Family. Journal of Marketing Management, 22 (9), 441-454.

Mason, M. and Pavia, T. (2006b). When the Family System Includes Disability: Adaptation in the Marketplace, Roles and Identity. Journal of Marketing Management, 22 (9/10), 1009-1030. 
Merton, R.K. (1972). Insiders and Outsiders: A chapter in the sociology of knowledge, The American Journal of Sociology, 78 (1), 9-47.

Mick, D.G. (2006). Meaning and mattering through transformative consumer research. Advances in Consumer Research, 33 (1), 1-4.

Miles, M.B. and Huberman, M.A. (1994). Qualitative Data Analysis. London, Sage.

Miller, D.L., Creswell, J. W., \& Olander, L.S. (1998). Writing and retelling multiple ethnographic tales of a soup kitchen for the homeless. Qualitative Inquiry, 4 (4), 469-491.

Murphy, R. (1990). The Body Silent. New York: W.W. Norton and Company.

Ozanne, J. (2009). Taking it to the Streets: Methodological Challenges of Doing Transformative Consumer Research on Health. Advances in Consumer Research, 36 (1), 143-144.

Palmer, A. and Ponsonby, S. (2002). The social construction of new marketing paradigms: the influence of personal perspective. Journal of Marketing Management, 18(1), 173-192.

Peñaloza, L. and Venkatesh, A. (2006). Further evolving the new dominant logic of marketing: from services to the social construction of markets. Marketing Theory, 6 (3), 299-316.

Phillips, M.J., (1990). Damaged Goods: Oral Narratives of the Experience of Disability in American Culture. Social Science Medicine, 30(8), 849-857.

Reay, D. (1996). Dealing with difficult differences: Reflexivity and social class in feminist research. Feminism \& Psychology, 6 (3), 443-456.

Scott, S. (1998). Here Be Dragons: Researching the Unbelievable, Hearing the Unthinkable. A Feminist Sociologist in Uncharted Territory. Sociological Research Online, 3 (1), http://www.socresonline.org.uk/socresonline/3/3/1.html 
Scott, L., Williams, J.D., Baker, S.M., Brace-Govan, J., Downey, H. Hakstian, A., Henderson, G.R., Loroz, P.S. and Webb, D. (2011). Beyond Poverty: Social Justice in a Global Marketplace. Journal of Public Policy and Marketing. 30 (1), 39-46.

Seidman, I. (2006). Interviewing as qualitative research: a guide for researchers in education and the social sciences. New York: Columbia University Press.

Shankar, A. and Patterson, M. (2001). Interpreting the past, writing the future. Journal of Marketing Management, 17 (5/6), 481-501.

Sieber, J.E. and Stanley, B. (1988). Ethical and Professional Dimensions of Socially Sensitive Research. American Psychologist, 43 (1), 49-55.

Stone, T. (2009), Reflection upon the use of existential-phenomenological methods to study elderly consumers in care homes. The Marketing Review, 9 (3), 213-229.

Strickland, S. (1994). Feminism, Postmodernism and Difference. In K. Lennon and M. Whitford (eds.), Knowing the Difference: Feminist Perspectives in Epistemology (pp. 265274), London: Routledge.

Tadajewski, M. (2010) Towards a history of critical marketing studies. Journal of Marketing Management, 26 (9/10), 773-824.

Thompson, C.J. (2002). A Re-Inquiry on Re-Inquiries: A Postmodern Proposal for a CriticalReflexive Approach. Journal of Consumer Research, 29 (1), 142-145.

Thompson, C.J., Locander, W.B., and Pollio, H.R. (1989). Putting Consumer Experience Back into Consumer Research: The Philosophy and Method of ExistentialPhenomenology, Journal of Consumer Research, 16 (2), 133-146.

The Voice Group, (2008). Reflections on collaboration in interpretive consumer research. Qualitative Market Research: An International Journal, 11 (2), 147-165.

Tillman, L.C. (2002). Culturally Sensitive Research Approaches: An African-American Perspective. Educational Researcher, 31 (9), 3-12. 
Todd, J., Rougier, N., O’Keefe, T. and Bottos, L.C. (2009). Does being Protestant matter? Protestants, minorities and the re-making of ethno-religious identity after the Good Friday Agreement. National Identities, 11(1), 87-99.

Van Mannen, J. (2011), Tales of the Field, $2^{\text {nd }}$ ed. Chicago: University of Chicago Press.

Warr, D. (2004). Stories in the Flesh and Voices in the Head: Reflections on the Context and Impact of Research with Disadvantaged Populations. Qualitative Health Research, 14(4), $578-87$.

Wasser, J.D. and Bresler, L. (1996), Working in the interpretive zone: conceptualising collaboration in qualitative research teams. Educational Researcher, 25 (5), 5-15.

Watts, J. H. (2008). Emotion, empathy and exit: reflections on doing ethnographic qualitative research on sensitive topics. Medical Sociology Online, 3(2), 3-14.

Woodby, L., Williams, B.R., Wittich, A.R., and Burgioet, K.L. (2011). Expanding the Notion of Researcher Distress: The Cumulative Effects of Coding. Qualitative Health Research, 21(6), 830-838.

Woodthorpe, K. (2007). My life after death: connecting the field, the findings and the feelings. Anthropology Matters, 9(1), 1-11. 
Figure 1: Researcher Vulnerability, Catalysts and Potential Outcomes

\begin{tabular}{|c|c|c|}
\hline Catalysts & Researcher Vulnerability & Potential Outcomes \\
\hline $\begin{array}{l}\text { Sensitive context } \\
\text { Physical context } \\
\text { Emotional exposure } \\
\text { Interpretivist and/or } \\
\text { qualitative research methods } \\
\text { Lone researcher paradigm } \\
\text { Closeness/Immersion } \\
\text { Empathetic Response }\end{array}$ & $\begin{array}{c}\text { Emotional distress } \\
\text { Threat to physical safety } \\
\text { Guilt } \\
\text { Fear } \\
\text { Frustration } \\
\text { Uncertainty } \\
\text { Isolation } \\
\text { Heightened level of stress }\end{array}$ & $\begin{array}{l}\text { Burn-out: Completion of } \\
\text { research project in jeopardy } \\
\text { De-sensitisation } \\
\text { Personal reflection } \\
\text { Researcher disempowerment }\end{array}$ \\
\hline
\end{tabular}

